\title{
A pedagogia científica de Bachelard: uma reflexão a favor da qualidade da prática e da pesquisa docente
}

Dirce Mendes da Fonseca

Centro Universitário de Brasilia

\section{Resumo}

0 presente artigo foi desenvolvido tendo como eixo analítico a obra de Gaston Bachelard na construção do "novo espírito científico", tendo como referência suas contribuições epistemológicas traduzidas na pedagogia científica e análise do esgotamento do positivismo como referencial da pesquisa em Ciências Sociais. Apresenta a epistemologia histórica de Bachelard - considera que todo conhecimento é polêmico e que, nesse sentido, as construções passadas devem ceder lugar às novas construções. Propõe a noção de rupturas para indicar uma forma mais científica de produzir ciências, a noção de processo dialético na produção de conhecimento científico e a concepção de conhecimento como progresso contínuo de retificação. Busca relacionar a pedagogia científica à prática pedagógica e apresenta as possibilidades de transformação no campo da formação docente e da pesquisa, a partir de uma visão peculiar de epistemologia e de uma prática científica crítica e reflexiva. Uma pedagogia científica que deve ter como preocupação desenvolver ações formativas e estar inserida numa dupla perspectiva - a educação entendida como prática social e histórica. Tais reflexões encaminham para a articulação teoria-prática e para a compreensão da pesquisa como uma atividade criativa. Desse processo, deve resultar a compreensão do fazer científico, da prática interdisciplinar, da articulação teoria-prática e do aprendizado integrado pesquisa/ensino.

\section{Palavras-chave}

Epistemologia - Metodologia - Pedagogia científica - Pesquisa, ensino e prática científica. 


\title{
Bachelard's scientific pedagogy: a reflection in favor of the quality of teacher practice and research
}

Dirce Mendes da Fonseca

Centro Universitário de Brasília

\begin{abstract}
This article takes its analytical axis from the work of Gaston Bachelard in the construction of the "new scientific spirit", and is based on his epistemological contributions as they appear in his scientific pedagogy and analysis of the demise of positivism as a research framework in the Social Sciences. The text introduces Bachelard's historical epistemology, in which all knowledge is regarded as controversial, and that, therefore, old constructions must give way to new constructions. It proposes the notion of rupture to specify a more scientific way to produce science, the notion of dialectic process in the production of scientific knowledge, and the concept of knowledge as a continual process of rectification. It seeks to correlate the scientific pedagogy with pedagogical practice, and shows the possibilities of transformation in the field of teacher education and research based on a particular view of epistemology and of a critical and reflective scientific practice. A scientific pedagogy that must have its eyes on developing formative actions and on having a double perspective: education understood as a social and historical practice. These reflections lead us to articulate theory and practice, and to understand research as a creative practice. From such process should come forth our understanding of what it means to do science, of interdisciplinary practice, of the articulation between theory and practice, and of the integrated learning of research and teaching.
\end{abstract}

\section{Keywords}

Epistemology - Methodology - Scientific pedagogy - Research, teaching and scientific practice. 
Este texto tem como objetivo apresentar as contribuições de Gaston Bachelard referentes à pedagogia científica e aos fundamentos epistemológicos que constituíram suas bases, bem como discutir metodologicamente a apreensão dessa pedagogia na prática científico-docente.

Parte-se do ponto de vista de que as discussões de Bachelard nesse campo teórico-epistemológico são importantes para o pensamento pedagógico, considerando que os pressupostos da pedagogia científica são, de certa forma, inseparáveis dos pressupostos epistemológicos que fundamentam, na visão do autor, "o novo espírito científico". Elas contribuem para refletir acerca de práticas científicas pedagógicas centradas em epistemologias de cunho racio-nalista e de práticas pedagógicas conservadoras e acríticas da realidade social, bem como sobre a forma de produzir conhecimentos centrados nos pressupostos e na visão positivista de ciência. Nesse sentido, as contribuições do autor têm reflexo na forma de pensamento e nas práticas pedagógicas que orientam a pesquisa.

Para a discussão da pedagogia científica e suas contribuições, faz-se necessário, ainda que de forma resumida, apresentar os referenciais que fundamentam a obra de Bachelard, considerando que o conceito de pedagogia científica está diretamente relacionado ao campo epistemológico que o autor desenvolve. Feita tais considerações, o texto procura pontuar os principais referenciais propostos pelo autor, a partir dos quais elabora o conceito de "pedagogia científica”. Tal conceito está fundamentado numa epistemologia dialógica e crítica.

A transformação da prática docente implica em mudança de concepção do próprio trabalho pedagógico, muitas vezes conservador, centrado em relações autoritárias, na reprodução e manutenção do conhecimento acrítico e deslocado da realidade e em métodos positivistas-racionalistas. É, nesse sentido, que a obra de Bachelard é atual e instigante, tanto do ponto de vista epistemológico como do ponto de vista metodológico.

Bachelard é um autor complexo para o seu tempo. No campo da epistemologia, ele tanto dialoga como se contrapõe à tradição científica fundamentada no cartesianismo, nos métodos de dedução predominantes na prática científica. Pensa a ciência como um processo de negação dos conhecimentos atuais. Acredita que a filosofia está sempre defasada em relação à ciência e insiste no caráter inovador do espírito científico contemporâneo. Para o autor, "o novo espírito científico" precisa ultrapassar os obstáculos epistemológicos que impedem a ciência de progredir. Critica as concepções continuístas da história da ciência e introduz a noção de ruptura para mostrar a idéia de descontinuidade da ciência. 0 espírito científico deve se formar enquanto se reforma.

Um ponto fundamental na obra de Bachelard (2000) é a ruptura que propõe com o determinismo científico, com o método cartesiano e com o pensamento objetivo. Para ele, a epistemologia cartesiana é uma epistemologia em crise. Na crítica da epistemologia objetivista, afirma que "o método cartesiano é redutivo, não é indutivo" (p. 121), e que os métodos de pesquisa, em algum momento do desenvolvimento do pensamento científico, perdem, conseqüentemente, a sua vitalidade. Contrapondo ao determinismo científico que se aplica e se prova nos fenômenos simplificados, à intuição, às impressões primeiras, ao equívoco das primeiras idéias, ele afirma que o pensamento complexo é um "pensamento ávido de totalidade" (p. 123). É essa noção de pensamento complexo que deve estar na base da pedagogia científica que alimenta a ciência moderna. Para Bachelard (2000):

$\mathrm{Na}$ realidade não há fenômenos simples; o fenômeno é um tecido de relações. Não há natureza simples, nem substância simples, porque a substância é uma contextura de atributos. Não há idéia simples, porque uma idéia simples, como viu Dupréel, deve ser inserida, para ser compreendida, num sistema complexo de pensamentos e experiências. A aplicação é complicação. As idéias simples são hipóteses de trabalho, conceitos de trabalho, que deverão ser revisadas para receber 
seu justo papel epistemológico. As idéias simples não são a base definitiva do conhecimento; aparecerão, por conseguinte, com um outro aspecto quando forem dispostas numa perspectiva de simplificação a partir das idéias completas. (p. 130)

A epistemologia de Bachelard rompe com as evidências cartesianas, propõe uma pedagogia do pensamento complexo e reafirma a necessidade de sempre reler o simples sob o múltiplo e a partir de uma visão de complexidade.

Permite um novo olhar sobre a prática científico-docente, ao introduzir o conceito de ruptura com a epistemologia cartesiana. Vale dizer que o pré-construído está posto, faz parte dos lugares comuns e está imerso no mundo social. As rupturas implicam pôr em suspenso as prénoções, os dados do senso comum, as formas de pensamento que orientam práticas científicas centradas nos enfoques estritamente racionalistaspositivistas. Destaca Bachelard (2000) que, na construção de objetos de pesquisa, há de considerar que o objeto sempre se apresenta como um complexo tecido de relações e, para apreendê-lo, tanto o pensamento quanto os métodos necessitam exercitar todas as dialéticas.

Ao romper com epistemologia cartesiana, essa forma de pensamento busca o complexo e o indeterminado, ensejando os fundamentos epistemológicos da razão aberta e do espírito científico. Apóiam-se, essencialmente, na retificação do saber e nas categorias históricas críticas, apreende o mundo social e os objetos do conhecimento nas suas múltiplas ralações, interações e complexidades. Tais categorias e referências embasam uma forma de pensamento que pode contribuir para fundamentar a pesquisa crítica e reflexiva. Os fundamentos epistemológicos centrados nos pressupostos da pedagogia científica inovam o fazer científico e o pensamento pedagógico.

\section{Para uma pedagogia científica}

0 autor, ao tratar da pedagogia científica, faz uma primeira reflexão sobre a filosofia da ciência e apresenta uma concepção de conhecimento científico como um "processo contínuo de retificação" movido pela superação dos obstáculos epistemológicos. Apela por um diálogo entre razão e experiência, por uma razão que procura desaprender, por uma metodologia consciente, o que significa pensar uma pedagogia "em ruptura com o conhecimento usual”, caracterizando, assim, por uma evolução metodológica, uma mudança de lógica, um profundo exercício de “todas as dialéticas”. É nesse sentido que se pode tomar a pedagogia bachelardiana com uma pedagogia criativa que permite instituir novos saberes a partir de rupturas com o senso comum, com a epistemologia cartesiana e permite pensar numa pedagogia dialética no sentido mais amplo. Uma pedagogia capaz de orientar os passos de educadores para se livrarem das visões estreitas e de todo o pragmatismo ingênuo.

Para Bachelard (2000), a noção de obstáculo epistemológico pode ser estudada no desenvolvimento histórico do pensamento científico e na prática da Educação, e nesta, afirma ele:

Muitas vezes me tenho impressionado com o fato de os professores de ciências, mais ainda, se possivel, do que os outros, não compreenderem que não se compreenda. Muito poucos são aqueles que investigaram a psicologia do erro, da ignorância e da irreflexão. (p. 168)

\section{Para ele, a tarefa do professor}

[...] consiste no esforço de mudar de cultura experimental, de derrubar os obstáculos já amontoados pela vida cotidiana, de propiciar rupturas com o senso comum, com um saber que se institui da opinião e com a tradição empiricista das impressões primeiras. Assim, o epistemólogo tem de tomar os factos como idéias, inserindo-os num sistema de pensamento. (p. 168)

Um fato pouco compreendido ou mal interpretado constitui um obstáculo, um 
contrapensamento. Assim, torna-se importante na formação do professor a reflexão e a apreensão da concepção de conhecimento que fundamenta a sua prática científica. Bachelard (2000) afirma que o problema do conhecimento científico deve ser pensado com base na noção de obstáculo. A superação de obstáculos se inicia com uma nova pedagogia, aquela que ele chama de pedagogia científica, na qual o esforço do professor consiste em fazer com que os alunos se afastem da cultura científica adquirida e da percepção apreendida na vida cotidiana pelo senso comum. É impossível educar por simples referência a um passado de educação. É necessário pensar numa ciência em mutação e num pensamento aberto que se renova. 0 "espírito científico" tem que se fundar, deformando-se. Assim, o conhecimento se estrutura na fronteira do desconhecido e do conhecido, instaurando a permanente necessidade de rupturas e abertura a uma dialética da descontinuidade, de olhares múltiplos para um mesmo objeto. Ainda no campo da noção de rupturas epistemológicas, o autor afirma que a Ciência se opõe à opinião. Em ciência, a opinião está na esfera de outros campos, nada é dado, tudo se constrói. O senso comum e as outras formas de manifestação, o conhecimento vulgar, a sociologia espontânea, a experiência cotidiana são opiniões, formas de expressão, que não representam e não têm o valor de conhecimento científico.

A epistemologia bachelardiana fundamentada no racionalismo aberto chama a atenção para o risco da não cientificidade das impressões primeiras e do pensamento simplista. Em Bachelard, epistemologia e pedagogia se entrelaçam para formar um pensamento orgânico que se renova e que não se conforma com as impressões primeiras e com os dados do senso comum e da apreensão da realidade por meios não científicos.

$\mathrm{Na}$ prática científica, alerta Bachelard (2001):

A opinião pensa mal; ela não pensa, traduz, necessidades em conhecimentos. Ao desig- nar os objectos pela sua utilidade, coíbe-se de os conhecer. Nada se pode fundar a partir da opinião; é necessário, antes de mais, destruí-la. Ela constitui o primeiro obstáculo a ultrapassar. [...] 0 espírito científico proíbe-nos de ter uma opinião sobre questões que não compreendemos, sobre questões que não sabemos formular claramente. É preciso, antes de tudo saber formular problemas. [...] É precisamente o sentido do problema que dá a marca do verdadeiro espírito científico. Para um espírito científico, todo o conhecimento é uma resposta a uma questão. Se não houver uma questão, não pode haver conhecimento científico. Nada é natural. Nada é dado. Tudo é construído. (p. 166)

A pedagogia científica instrui a prática e a cultura científicas para a aquisição de uma forma de conhecimento e de pensamento que, na visão de Bachelard, pode se traduzir automaticamente numa reforma do espírito.

0 autor postula a construção de uma cultura a partir da ciência como a grande estruturadora dessa nova pedagogia. Tendo em vista tais referências, a epistemologia que fundamenta a prática científica contém uma filosofia e expressa uma visão de mundo sobre a problemática da produção de conhecimento. A pesquisa se desenvolve com a formação do professor, da epistemologia e da concepção de conhecimento ou de teoria do conhecimento nas quais sua prática está fundamentada. A compreensão epistemológica do professor torna, sem dúvida, sua atividade científica mais consolidada e permite fundamentar as bases da pesquisa como dimensão da pedagogia consciente. 0 autor chama de pedagogia consciente aquela que denota novas práticas científicas em rupturas com os paradigmas cartesianos-lógicos-racionais e com a apreensão da realidade pelos dados do senso comum.

A ciência e a prática científica têm raízes em várias epistemologias (epistemologia lógica, genética, histórico-crítica). No entanto, é no interior de concepções abertas e dialéticas que 
o conhecimento pode encontrar a possibilidade de renovação, de construção e de reconstrução. Tais concepções epistemológicas indicam ao professor a adoção de metodologias conscientes que privilegiem uma pedagogia em constante ruptura com o conhecimento usual. "Chega uma altura em que o espírito gosta mais daquilo que confirma o seu saber do que daquilo que o contradiz, prefere as respostas às perguntas" (Bachelard, 2001 p. 167). É esse o risco de o professor ensinar sempre as respostas certas. Na pedagogia científica, o erro se instrui a partir de uma dinâmica pedagógica que coloque o conhecimento em permanente estado de crise, criando sempre a necessidade de retificar-se.

Na visão de Bachelard, a formação do professor contemplaria uma prática pedagógica, "uma metodologia consciente" que privilegiasse uma pedagogia em ruptura com o conhecimento usual. Assim, "de um modo mais positivo, apreender-se-á a essência da psicologia do espírito científico na reflexão pela qual as leis descobertas na experiência são pensadas sob forma de regras aptas a descobrir novos fatos" (Bachelard, 2000, p. 122). 0 verdadeiro espírito científico se forma na dialética estabelecida por tensões e na abertura integral. Assim, dialetizar o pensamento é aumentar a possibilidade de apreender e de criar cientificamente fenômenos complexos, de regenerar novas dimensões não percebidas por meio do pensamento ingênuo e acrítico. A produção de conhecimento e os processos pedagógicos se justapõem.

A nova pedagogia científica pensada por Bachelard é essencialmente crítica e estimula professores e alunos a exercitarem o pensamento aberto na busca de fenômenos e problemáticas complexas e na capacidade de formular questõesproblemas e de construir objetos de pesquisa, "procurando no real aquilo que contradiz conhecimentos anteriores" (Bachelard, 1991 p. 13). Poder-se-ia dizer que Bachelard, ao tratar da pedagogia científica, trata também da pedagogia do pensamento. Com tal posicionamento, ele faz um apelo ao exercício da prática da "filosofia do não", a que procede, em nós e fora de nós, uma atividade construtiva. Essa filosofia afirma que 0 espírito é, no seu trabalho, um fator de evolução. Pensar corretamente o real é aproveitar as suas ambigüidades para modificar e alertar o pensamento "a criar condições para a dialetização”. Tal pedagogia incentiva relações pedagógicas construtivas e permitem desenvolver a capacidade de autonomia intelectual, de construção de novos conhecimentos e de novas questões científicas que possam se contrapor à visão empiricista.

Uma pedagogia fundamentada numa epistemologia aberta e reflexiva fundamentará uma interpedagogia do ensino, o que, sem dúvida, propicia uma ressignificação da relação pedagógica e da prática científica. Isso estimula dinâmicas criativas.

A relação pedagógica implica interações humanas e psicológicas, de confiança e de respeito intelectual. Desenvolve-se a partir do interesse do professor no crescimento intelectual, moral, ético e científico do aluno e, como assinala Bachelard, um desejo de que o aluno possa superar o mestre. Todo mestre deve formar seus discípulos. No entanto, a Educação carece dessa dimensão que, aos poucos, está se perdendo devido à racionalidade, à burocracia acadêmica, ao controle pelo controle de um saber instrumental prático e pouco estimulante do ponto de vista intelectual. A vida acadêmica e a intelectual necessitam de predisposição afetiva e, ao mesmo tempo, de uma inquietação permanente de uma imaginação crítica e reflexiva.

Para Bachelard (2001), toda cultura científica deve começar por uma catarse intelectual e afetiva e pela compreensão de uma "consciência em mutação" e "por um ensino não dogmático". 0 que é um ensino dogmático? Que concepções e práticas científicas esse ensino gera? São questões que interessam ao campo da Educação e da Pedagogia.

Para a ciência e o conhecimento, entendidos como um processo contínuo de retificação, é tarefa pedagógica do professor "colocar a cultura científica em estado de mobilização 
permanente, substituir o saber fechado e estático por um conhecimento aberto e dinâmico, capaz de se reconstruir e de se retificar. Segundo esse ponto de vista, a pedagogia da razão deve valer-se de todas as oportunidades de raciocinar e de pensar, empregando todas as variações do pensamento. Pergunta Bachelard (1991): "Que seria uma função sem possibilidade de funcionar? Que seria uma razão sem possibilidade de pensar?" (p. 135). Devem ser aplicados todos os ensinamentos da ciência, por muito especiais que sejam, para a aquisição de uma forma de conhecimento que se traduza, automaticamente, numa "forma de espírito (p. 118). Japiassu (s/ d) complementa esse pensamento no sentido da renovação no campo da pesquisa científica:

A dificuldade e a discussão fazem parte do dinamismo psicológico da pesquisa científica. E não só da pesquisa, mas também da pedagogia da ciência. Tanto o trabalho científico de pesquisa quanto o de seu ensino exigem que os pesquisadores e os educadores criem dificuldades para si próprios. 0 importante é que saibam criar dificuldades reais e eliminar os obstáculos falsos ou as dificuldades simplesmente imaginárias. Devem sentir uma espécie de apetite pelos problemas difíceis. (p. 73)

Enquanto Bachelard sugere uma pedagogia da superação, uma epistemologia da pluralidade, da razão aberta para pensar "e para tentar desaprender muito daquilo que aprendeu”, Weber (1982) apela para o que chama de integridade intelectual do professor. No texto "A ciência como vocação”, define a vocação científica como uma vocação íntima e enfatiza a tarefa do professor como aquela de "servir aos alunos com o seu conhecimento e experiência e não impor suas opiniões pessoais". Para este, não é possível demonstrar cientificamente o dever de um professor:

[...] só podemos pedir dele que tenha integridade intelectual de ver que uma coisa é apresentar os fatos, determinar as relações matemáticas ou lógicas, ou a estrutura interna dos valores culturais, e outra coisa é responder a perguntas sobre o valor, cultura e seus conteúdos individuais, e à questão de como devemos agir na comunidade cultural e nas associações políticas. São problemas totalmente heterogêneos. Se perguntarmos porque não devemos nos ocupar de ambos os tipos de problemas na sala de aula, a resposta será: porque o profeta e o demagogo não pertencem à cátedra acadêmica. (p. 172-173)

Tal afirmação é importante para a reflexão da atividade prática docente. Uma contribuição da pedagogia científica é noção de catarse intelectual e afetiva na relação pedagógica. A atividade acadêmica intelectual se dá em ambiente de dúvida e inquietação. Assim, todas as práticas científicas e pedagógicas devem estar lastreadas por relações positivas. Com isso, o autor confere à prática acadêmica e científica um significado pedagógico-afetivo. O dogmatismo desconstrói toda criatividade e gera uma paralisa mental. 0 professor, na prática pedagógico-científica, pode ser muito menos alguém que ensina e mais alguém que desperta, estimula, provoca, questiona e se deixa questionar. Tal atitude permite estabelecer relações pedagógicas colaborativas, abertas e construtivas. A ambiência afetiva e pedagógica estimulará, com certeza, o aluno a criar, criticar, produzir, inovar, pesquisar etc.

A pedagogia formativa, no sentido que expressa Bachelard, pressupõe formação científica e vocação para a ciência. Tais pressupostos implicam mudança de cultura na prática científica e nos processos pedagógicos, de forma a tornar o pedagógico mais científico, e este, mais pedagógico.

Nessa perspectiva, a prática pedagógica deve refletir a prática científica e vice-versa. Segue-se que tornar o científico mais pedagógico significa utilizar formas de pedagogia que situem os alunos como sujeitos críticos, que 
problematizem o conhecimento, que lancem novas questões, gerando novos desafios e novas questões-problema/soluções, "retificando" a ciência e os métodos científicos.

Assim, para a ciência e para o espírito científico, todo conhecimento representa resposta a uma dúvida, a uma questão. É o sentido da dúvida e de problema é que dá a marca do verdadeiro espírito investigador. Se não houver problemas, não há respostas. A pedagogia científica de que fala Bachelard procura estimular o aluno na capacidade de inquietarse, de colocar sempre novas questões e de estar em permanente estado de inconformismo com o conhecido, com a ciência dita "normal" e com o conhecimento estabelecido. Para a ciência, a opinião representa uma desconstrução.

0 pensamento científico é também um pensamento político: remete ao uso, ou seja, à utilidade social da pesquisa. Assim, uma política de pesquisa deverá ser, também, uma política social. A pedagogia científica, vista sob a ótica de Bachelard, enseja maior interação entre aluno e professor, fortalecendo os vínculos acadêmicos e a formação de docente, o aprofundamento teórico metodológico e a capacidade intrínseca do risco e da incerteza.

Assim, a prática docente cria oportunidades para o aluno desenvolver processos sistemáticos de pesquisa, participando de todas as fases da pesquisa, desde a elaboração do projeto de desenvolvimento e conclusão da pesquisa. Nesse sentido, pesquisa e ensino constituem processos interligados e interativos, no qual se possa criar uma cultura em que o mestre se torne verdadeiramente aluno e em que o aluno se torne realmente mestre.

Bachelard (2001) compreende a prática pedagógica quando ela se realiza no interior de uma "interpedagogia do ensino", o que significa dizer que todo aquele que aprende só saberá verdadeiramente quando sua aprendizagem for consubstanciada na prática de ensinar. Por outro lado, a cultura científica coloca a necessidade permanente de inquietar a razão, dialetizar o conhecimento. Desconstruir a ciência já construída, no pensamento de Bachelard, seria depreender reflexões pedagógicas que instruem a prática científica e o pensamento aberto.

Uma pedagogia científica é antes de tudo uma pedagogia do pensamento e, assim, estará inserida em uma dupla perspectiva - a educação, entendida como uma prática filosófica, histórica e social, e uma perspectiva crítica. Tais reflexões encaminham para a articulação epistemologia/ pedagogia científica e para a compreensão da pesquisa como uma atividade criativa e crítica de produção de novos conhecimentos. Desse processo, deve resultar a compreensão do fazer científico, da prática interdisciplinar, da articulação teoria/prática e do aprendizado integrado pesquisa/ensino no processo de produção do conhecimento. Dessa forma, o professor/orientador exerce duplamente a ação pedagógica: a de ensinar e pesquisar, a de aprender e ensinar. Ambas são atividades interligadas.

Esse enfoque de pesquisa, interligada à ação pedagógica, pressupõe a atuação do pesquisador e do aluno sobre o objeto do conhecimento e o desenvolvimento de práticas científicas mais científicas. Assim, a formação do aluno estará voltada para o desenvolvimento da autonomia intelectual. Na formação do aluno/pesquisador, um aspecto importante é, sem dúvida, a formação multidisciplinar e interdisciplinar, de tal forma que um problema possa ser compreendido pelos conceitos e métodos de outras ciências. Uma ciência se torna objeto da outra.

0 caráter multidisciplinar amplia a formação do aluno e o exercício do pensamento complexo permitindo estabelecer diálogos teórico-metodológicos mais apropriados à produção de conhecimento. No entanto, para pensar o ensino articulado à pesquisa, torna-se necessário reverter a lógica do ensino tradicional e integrá-lo à lógica da pesquisa. Integrar ensino e pesquisa pressupõe uma nova relação com o aluno e uma nova condição de ensino. 0 aluno é o centro da ação pedagógica. Ele deve produzir, refletir, observar, indagar e, essencialmente, adquirir formação e ações básicas de quem investiga. Este processo pedagógico 
poderá contribuir para desenvolver sua própria autonomia intelectual, tornando-se um intelectual independente, capaz de assumir atitudes científicas no seu futuro profissional.

A discussão da pedagogia científica e das bases epistemológicas que a constitui teve como objetivos refletir a prática da pesquisa e apresentar referenciais para refletir sobre uma nova pedagogia centrada na epistemologia de Bachelard. Assim, é de fundamental importância desenvolver práticas e metodologias que levem o aluno a pensar criticamente, a desenvolver sua própria autonomia intelectual, a desenvolver uma atitude de busca de aprender num processo contínuo a partir de um pensamento dialetizante, a utilizar conceitos e novas elaborações, como instrumento de construção e reconstrução de novos saberes.

0 pensamento crítico desenvolve práticas pedagógicas também críticas, geradoras de novas questões, estabelecendo diálogos multidisciplinares com outras áreas de conhecimento. Uma pedagogia crítica propicia as condições que dão ao campo acadêmico e científico a oportunidade epistemológica de formular, permanentemente, questões-problema. Assim, o verdadeiro educador precisa reconhecer-se em estado de "infância cerebral".

Bachelard (2001) apela por uma razão aberta; por uma nova comunicação pedagógica; por uma escola que deve ser contínua ao longo da vida; por uma educação permanente; e por uma pedagogia do descontínuo e da incerteza. Na prática educativa, chama a atenção para dois aspectos pedagógicos: o do mestre que, em um processo contínuo de aprender, se converte em estudante, pois "permanecer estudante deve ser o anseio secreto de todo mestre" e, por outro lado, "aquele que aprende deve ensinar", consubstanciando uma interpsicologia do ensino.

0 espírito cientifico é, essencialmente, uma retificação do saber, um alargamento dos quadros do conhecimento. Julga seu passado histórico, condenando-o. Sua estrutura é a consciência de suas faltas históricas. Cientificamen- te, pensa-se o verdadeiro como retificação histórica de um longo erro, pensa-se a experiência como retificação da ilusão comum e primeira. Toda a vida intelectual da ciência move-se dialeticamente sobre esse diferencial do conhecimento na fronteira do desconhecido. "A própria essência da reflexão é compreender que não se compreenderá" (Bachelard, 2000, p. 147).

\section{Considerações finais}

Em suma, este artigo buscou focalizar a discussão epistemológica da obra de Bachelard com vistas a apreender o conceito de pedagogia científica e suas relações com as práticas pedagógicas: o ensino e a pesquisa. Focalizou a contribuição de Bachelard na posição do objeto como perspectiva das idéias, o que significa que os fatos não contêm uma única autonomia de verdade. Pela introdução da noção de ruptura epistemológica, desenvolve uma radical oposição ao pensamento positivista e cartesiano. Mostra que o progresso do espírito científico se faz por rupturas com o senso comum e que a experiência científica deve contradizer a experiência orientada pelo senso comum.

Da reflexão aqui pontuada, alguns pontos merecem ser destacados:

- A reflexão sobre a produção de conhecimento é uma reflexão que afeta os pressupostos da racionalidade científica e da racionalidade pedagógica.

- A discussão epistemológica do fazer científico não pode estar dissociada da prática docente, considerando que "o ato de ensinar não se destaca tão facilmente quanto se crê, da consciência de saber" (Bachelard, 1997, p. 19). - 0 autor reforça o conceito de metodologia consciente que se depreende de uma prática científica crítica e reflexiva e atenta às rupturas epistemológicas do saber apreendido no cotidiano a partir das impressões primeiras.

- A nova pedagogia de Bachelard é, antes de tudo, epistemológica, a qual pode contribuir para alimentar o debate e o pensamento pe- 
dagógico para uma nova cultura científica.

- Assim concebido, o conceito de pedagogia cientifica não se separa da forma de pensamento e da epistemologia que o constitui.

A epistemologia de Bachelard tem, pois, uma conseqüência na forma de produzir ciência e na construção epistemológica centrada na idéia do conhecimento construído historicamente e reconstruído a partir de retificações permanentes. Todas essas questões constituem um suporte para as discussões metodológicas e para uma prática científica aberta, crítica e reflexiva no campo da Pedagogia e da Formação Docente.

\section{Referências bibliográficas}

BACHELARD, G. A epistemologia. Lisboa: Edições 70, 2000.

A filosofia do não. Lisboa: Abril Cultural, 1991.

0 novo espírito científico. Rio de Janeiro: Tempo Brasileiro, 2001.

.0 racionalismo aplicado. Rio de Janeiro: Zahar, 1997.

JAPIASSU, H. Para ler Bachelard. Petrópolis: Vozes, (s.d).

WEBER, M. Ensaios de sociologia. Guanabara: Rio de Janeiro, 1882.

Recebido em 15.08.07

Aprovado em 16.06 .08

Dirce Mendes da Fonseca é professora aposentada da Faculdade de Educação da Universidade de Brasília (UnB); coordenadora do Núcleo de Estudos da Infância e Juventude do Centro de Estudos Multidisciplinares (CEAM) da UnB; professora do programa de Mestrado em Direito do Centro Universitário de Brasília (UniCEUB), é autora de livros e artigos no campo da gestão e da política educacional. 